associating in the movement many who were opposed to its real objects. The trick succeeded. A Journal committee was appointed, and under its jurisdiction the name of the Journal was altered, and the Provincial Medical and Surgical Association, as such, ceased to exist. I will not pain you with recalling to your recollection the first fruits of this disastrous proceeding. Influenced by that unscrupulous body, who have on all occasions strenuously endeavoured to keep down the medical practitioners of the country districts the Journal became the exponent of their exclusive views. A case occurred. A surgeon to an hospital had been expelled from his office for what was regarded as a flagrant attack upon his colleagues. The editor of the Journal sided with him; and, totally forgetful that it ought to represent the opinions of nearly 2000 of our members, sold to two persons interested in the contest an entire edition, which was circulated gratuitously to every member of the profession throughout the kingdom. Such a proceeding could scarcely have been justified, even had the actors in this affair been influenced by motives which were calculated to be beneficial to the profession at large.

But mark! a short time afterwards two gentlemen were placed in difficulty in consequence of an unsuccessful operation at one of our Hospitals, in which one of them was the chief actor, and the other at best but an assistant. It was a case deeply interesting to all of us, because at any moment any one of us might have been placed in the same position. What did the Journal do? Did it stand between the aggrieved parties and the public? Did it endeavour to extenuate what was at most a mistake-a mistake which might have occurred to the first and foremost in the practice of surgery? No! It sought by every means in its power to injure these gentlemen, and, under the guise of a canting philanthropy, talked of the rights of the poor, and the ignorance of incompetent surgeons. It is unnecessary for me to point out to you the motives which actuated the editor on these occasions. They are too transparent, and can only excite our disgnst and indignation-let that pass. Not satisfied with bringing the Journal to London, the clique, backed by that eccentric, fluent, and mistaken calculator, Dr. Cowan, of Reading, determined still further to separate our interests from theirs at the Manchester meeting. To effect this, the most unscrupulous means were resorted to by what Dr. Conolly justly denominated a "packed meeting." Dr. Cormack, in addition to his editorial duties, was appointed secretary to the Association! This, in fact, entirely separated our interests from those of the London clique. The Worcester council, it is true, remained the same in name, but as an executive body ceased to exercise any influence upon our career. The nature of the opposition with which you have to contend, is strikingly illustrated by the mode in which the "packed" meeting at Manchester performed the most unjustifiable act alluded to. They set at defiance the laws of the Association which for twenty years had regulated our proceedings. The very appointment of a London secretary was an infringment of the fundamental laws of our body. But the insult to us was perpetrated. Dr. Cormack became secretary by the votes of the "packed" meeting; and now appears, with his friend Dr. Cowan, to set us at defiance. Need I allude even for a moment to the treatment which our able and amiable associate, Dr. Lyon, has been exposed with reference to this matter? Surely a greater outrage on justice and good manners was never perpetrated-an outrage without an excuse, or even a palliation. Woll might Mr. Vicary declare that he "left Manchester strongly disgusted with all the proceedings." But observe the miserable subterfuge to which the editor resorts to justify his conduct with respect to the suppression of our communications, when not favourable to his manageanent of the Journal, or on other points in which we differ from him on Association matters. His interest does not allow him to fill the Journal with controversial or party matters. Let me remind you that this is the conscientions editor who for weeks occupied his Journal-for it is not ours-with subjects of the most irritating and disgraceful character; who sold an edition of the Joumal to gratify personal feelings; and saturated us, ad nauseum, with reports of the famous O'Connor row, by which the profession was insulted and scandalized by the low personalities of the discussions. This is the same editor who for weeks made the Journal an Evangelical Magazine. To gratify whom? -a miserable section of the Association. Allow me also to remind you, that the week after his most impudent notice to suppress whatever communications he pleased, and his offensive offer to print the letters of Dr. Lyon as an advertisement, at his "own expense" a long letter from Mr. Henry Ancell appears in the Journal in defence of its management, and in support of the doctrine that a Journal is the main object of the
Association. This letter, recollect, is in favour of Dr. Cormack, and of course is inserted in the body of the work to the extent of several columns! Turn over a few pages: the offensive advertisement appears! But who is Mr. Ancell? One of the most active of the London clique, and the late secretary of an Institute which had for its object the establishment of a new college of apothecaries, and the sinking of the honourable title of "surgeon" to that of "general practitioner"-a scheme which would have probably been carried, in spite of the remonstrances of the great body of surgeons throughout the country, but for the unceasing efforts of an independent press. And what has been the result of all this cliquismlaw breaking, personal abuse, cant, and the suppression of communications which told the truth, and were disagreeable to Dr. Cormack? We have an Association in a state of disorganiza. tion, with a council powerless to effect any beneficial change. We have a Journal condncted in a manner and with a spirit that has disgraced the profession; and which, from its scurrility and personal attacks, and low ideas of editorial morality, has made the " honour and dignity" of the Association a byeword and a sneer! We are encumbered with a formidable debt, for which each of us is individually responsible. We profess to number upwards of 2200 members, when in reality they are not more than 1800 , and these are daily decreasing.

Such, gentlemen, are some of the results of the past year, arising from the low, personal, and party spirit, which has characterized the Journal. I make no apologies for address. ing you through the pages of THE LANCET-the voice of re. monstrance will not reach you through that which is styled your own Journal. I beg to remain, gentlemen,

Your faithful servant,

ONe of the Original Members of the Provincial Medical

Dec. 30,1854 . and Surgical Assoctation.

ON THE MICROSCOPIC APPEARANCES IN THE SPUTA; AND ON FATTY DEGENERATION OF THE BLOODVESSELS IN PULMONARY TUBERCLE.

To the Editor" of The Lancer.

Str,-As your "Reviewer" requests communications upols the microscopic appearances of the expectoration in cases of phthisis, I forward the following extract from an essay, the publication of which has been for some time awaiting the final arrangements of "the powers that be," in the Provincial Medical and Surgical Association, as to the mode and medium :-

"Sputa.-If such be the real course pursued by the local disease, we shall naturally expect to find some evidence of fatty epithelial calls being cast off from the air-vesicles in the expectoration at the commencement of phthisis. This corroboration is not wanting. I have made careful examinations of the sputa in cases in which the deposition of tubercle appeared threatening, but in which noauscultatory proof was detectible; in cases of phthisis in its earliest confirmed stage, and in others where the disease was of old duration and in its third stage. The following is the sum of these observations on the sputa, in impending, incipient, and established phthisis :-

"Common to all.-Flat pavement epithelium, with sharp, clear, nucleolated nucleus, entire or partially dissolved, from mouth or pharynx. Bronchial columnar epithelium. Filmy cells, containing two or three dim granulous nuclei from tonsils. Pigment cells.

"Impending Tuberculization of Lungs. - Expectoration grey, glairy, adhesive; bronght up chiefly when dressing in the morning, and scarcely noticed or thought of by the patient. If innocent, (which, of course, it generally is, it consists merely of round, nebulous, mucous cells, in transparent adhesive mucus. If threatening, it presents in addition single cells, or small flakes of flat epithelium from the air-vesicles, fattily degenerating, and bronchial columnar epithelium also presenting various degrees of fatty degeneration.

"Incipient Tuberculization. - The same as the above; and in addition, red blood-corpuscles, more or less shrivelled and faded, enveloped in a filmy cell; a few large, many-nucleated cells; granules; and frequently small casts of air-vesicles and the ultimate bronchi, in which are plainly visible epithelial cells in various sizes and various stages of fatty degeneration. So constantly have I met with enveloped blood-corpuscles in sputum which betrayed no appearance of blood to the naked eye, that $I$ suspect this microscopic hæmoptysis is seldom, 
perhaps never, altogether absent in those cases of commencing phthisis in which the more obvious expectoration of blood is wanting.

" Established Phthisis. - The same as the last, largely mixed up with corpuscles of pus and mucus. Free tubercle-nuclei occasionally, in small quantity.

"Large Suppurating Carities.--Absence of specific tuberclecells, except portions of opaque tubercle itself happen to be expectorated. Habitually, little else than pus and mucus, and large granulous cells, unless confervoid vegetations be superadded, which is not unfrequent.

"The microscopic appearances presented by the expectoration are most special and characteristic in the early stage, when other physical evidence is least marked; and may be re-enumerated as consisting of fatty epithelial cells, single or in patches; fatty bronchial cylinder-epithelium ; casts of airvesicles lined with fatty epithelium; and microscopic hæmoptysis, i.e., enveloped red blood-globules. These are enough to indicate that consumption is threatened. When the manynucleated cells and special free nuclei of tubercle are superadded, no doubt can remain. All these I have repeatedly found in cases where the patient was not apprehensive of phthisis, but complained only of general malaise or dyspepsia, as well as in other cases in which phthisis was feared, but was not supposed to be yet in active existence."

I may remark, that it is no fair test of the accuracy of these observations, to adduce cases of phthisis in which they are not confirmed. Here everything depends upon the stage of the disease, and upon the number of observations made. Nor even will the occurrence of similar appearances in persons who do not afterwards follow the ordinary course of phthisis, invalidate them. I believe that a small amount of tuberculization of the lungs takes place in many persons unknown and unsuspected. How many have spit up small quantities of blood at some early period of life, without paying much attention to the circumstance, who never become phthisical? On the other hand, we are not at all in a position to speak dogmatically as to"the value of the appearances described as means of certain diagnosis. I consider them as aids, and find them to be so in practice. But no prudent man will decide a difficult question without taking into account all the grounds he can obtain for his judgment, and checking one inference by another. Understood in this sense, we have not at present to settle what microscopic appearances shall, for the future, be considered to be pathognomonic of tuberculization in the lungs, but simply to observe what appearances are commonly to be noticed in such cases at different stages. In short, for some time yet to come, we have merely to observe, and not to dogmatize.

Though not strictly pertaining to the subject-at least, I have never found portions of fatty bloodvessels amongst the matter expectorated-I may be allowed to make another extract.

"Small Bloodvessels in a state of Fatty Degeneration.-I have hitherto found these once only in large, grey, semi-transparent, miliary tubercles which lay as distinct nodules in uninflamedlung, and of which the blastenia was fibrillated and contained nucleated tubercle-cells, free nuclei, and no granules. Near to the portions of fattily-changed bloodvessels, shrivelled red corpuscles, and orange as well as black pigment, were found amongst the tnbercle-corpuscles imbedded in the tenacious fibrillated matrix. The tubercles were of larger dimensions than miliary tubercles ordinarily are, averaging the size of duck-shot, and including, of course, within each many air-vesicles. The right lung was strewn throughout with such tubercles, many of them quite cretified, some partially so; none softening, or becoming yellow in the centre otherwise than from cretifaction; none cornified. The lung was for the most part quite free from inflammation, expansile, non-adherent throughout, and partially emphysematous in front. This emphysema had every appearance of being recent, and probably dated either from the occurrence of severe epileptic fits, which supervened twice during the last month of life, or from the very protracted act of dying. The left lung was universally adherent, formed a mere bag, and contained about three pints of pus. The patient (sent to me by Mr. Bottomley three years since) had then had an immense cavity for some years. His age was twenty-eight.

"In the grey tubercles the fatty bloodvessels were unmistakable, having a clear defined outline, dividing into branches of considerable length, and having no openings or connexions with the adjoining elements. The centre of the vessel was bright and translucent, and the whole was studded with dim granules and oil-dots of various sizes. The patient had suffered from copions and repeated hæmoptysis two years before his denth.
"Considering how many cases of phthisis spring into noticeable activity coincidently with an attack of hæmoptysis, - the patient so commonly declaring that his chest was strong and his health good until he suddenly " broke a bloodvessel," which led to consumption, - this fact of fatty degeneration of small bloodvessels in the lungs, where no inflammation yet exists, at the e.rrliest stage of the highest form of tubercle, whilst as yet it occasions neither pain nor organic irritation of the lung, is valuable and explanatory. No doubt such a degenerated vessel, under some temporary muscular exertion or mental excitement, does literally "break;" and the flow of blood is then a veritable hæmorrhage from a patulous vessel, and not a mere transudation like that through the mucous membrane of the stomach in coffee-ground vomit. If so, the popular phraseology is correct.

"I have never found bloodvessels in a yellow tubercle; and these fattily degenerate vestiges in certain grey tubercles evidently represent the bloodvessels which originally belonged to the lung, and not vessels newly formed because of, or in any sense belonging to, the tubercle." *

I am, Sir, your obedient servant,

Torquay, December, 1854 . C. Radclyfee Hati, M.D.

\section{THE EXTENDED APPLICATION OF MEDICAL INSTRUCTION.}

To the Editor of THE LANCet.

SIR,-Your leader on the extended application of clinical teaching, in the last number, must have afforded solid satis faction to every lover of surgery awake to its present requirements. I have but recently completed a lengthened tour to all the great surgical schools of the European continent, and have been forced to the conclusion that, relatively, I might almost say absolutely, the provisions for teaching surgery clinically everywhere exceed those made in London. They do so even in such towns as Tubingen, Prague, Pavia, Pisa, Florenoe, Bólogna, Lyons, and Strasburgh, to say nothing of Berlin, Vienna, and Paris.

You have pointed to some defects in the system prevalent amongst us, and suggested a remedy; be pleased to grant me space for a few comments.

In general terms it may safely be asserted that undue importance is relatively attached to the higher operative surgery, and particularly to its mere manual exercise. It is reserved for appropriate days and hours, and the entire proceeding renders the expression, "surgical theatre," one of the most literally appropriate in the English language. What is the object for crowding together in one hour as many great operations as possible? If it be imparting instruction, the means are ill suited to the end. One or two operations during the surgeon's visit, with indications, steps, and probable results, thoroughly well considered, would be more in accordance with the laws of intellectual culture. The mind can no more than the stomach digest a rapidly-gulped, huge pile of heterogeneous. food, however in itself nutritious.

However anxious the surgeon may be, so large is the amount of work to be got through on an operating-day, (why did Liston, that incarnation of the surgical spirit, disapprove of operating-days?) that the best powers, backed by the strongest will, cannot suffice to convey to the assembled learners that amount of information which is indispensable to render all the bearings of the manual proceedings intelligible, as they should be to prove useful.

Let any one reflect how little the mass of those who witness the operation see of the patients afterwards. The housesurgeon and his dressers attend to the wounds in undisturbed quietude. The beautiful process of healing, the havoc of the sloughing phagedæna, the bright, flashing, and dim jaundiced eye of the delirious and pyomic patients respectively, are, with all their concomitants, the privileged lot of these diligent officers. Truly, those who walk the hospital (another very literally correct expression) see the sores at the surgeon's visit, but the dressing has been done two or three hours previously, and with it the great opportunity of learning gone. This is merely an instance. Is it not marvellous how this custom should have prevailed so long among practical Englishmen? The surgeon's visit, to be a demonstration of clinical surgery, should be a waiting visit-all the wounds dressed and the patients examined in his presence. In Dupuytren's clinique, all the fractures were put up, when required, a

* The various points referred to were largely illustrated in the drawings submitted to the meeting of the Association; and will be so illustrated whenever the essay is published. 